\title{
Neovascularization of coronary tunica intima (DIT) is the cause of coronary atherosclerosis. Lipoproteins invade coronary intima via neovascularization from adventitial vasa vasorum, but not from the arterial lumen: a hypothesis
}

Vladimir M Subbotin*

Correspondence: vladimir.m. subbotin@gmail.com

602 Samuel Drive, Madison, W! 53717, USA

\begin{abstract}
Background: An accepted hypothesis states that coronary atherosclerosis (CA) is initiated by endothelial dysfunction due to inflammation and high levels of LDLC, followed by deposition of lipids and macrophages from the luminal blood into the arterial intima, resulting in plaque formation. The success of statins in preventing CA promised much for extended protection and effective therapeutics. However, stalled progress in pharmaceutical treatment gives a good reason to review logical properties of the hypothesis underlining our efforts, and to reconsider whether our perception of CA is consistent with facts about the normal and diseased coronary artery.
\end{abstract}

Analysis: To begin with, it must be noted that the normal coronary intima is not a single-layer endothelium covering a thin acellular compartment, as claimed in most publications, but always appears as a multi-layer cellular compartment, or diffuse intimal thickening (DIT), in which cells are arranged in many layers. If low density lipoprotein cholesterol (LDL-C) invades the DIT from the coronary lumen, the initial depositions ought to be most proximal to blood, i.e. in the inner DIT. The facts show that the opposite is true, and lipids are initially deposited in the outer DIT. This contradiction is resolved by observing that the normal DIT is always avascular, receiving nutrients by diffusion from the lumen, whereas in CA the outer DIT is always neovascularized from adventitial vasa vasorum. The proteoglycan biglycan, confined to the outer DIT in both normal and diseased coronary arteries, has high binding capacity for LDL-C. However, the normal DIT is avascular and biglycan-LDL-C interactions are prevented by diffusion distance and LDL-C size $(20 \mathrm{~nm})$, whereas in CA, biglycan in the outer DIT can extract lipoproteins by direct contact with the blood. These facts lead to the single simplest explanation of all observations: (1) lipid deposition is initially localized in the outer DIT; (2) CA often develops at high blood LDL-C levels; (3) apparent CA can develop at lowered blood LDL-C levels. This mechanism is not unique to the coronary artery: for instance, the normally avascular cornea accumulates lipoproteins after neovascularization, resulting in lipid keratopathy. 
Hypothesis: Neovascularization of the normally avascular coronary DIT by permeable vasculature from the adventitial vasa vasorum is the cause of LDL deposition and CA. DIT enlargement, seen in early CA and aging, causes hypoxia of the outer DIT and induces neovascularization. According to this alternative proposal, coronary atherosclerosis is not related to inflammation and can occur in individuals with normal circulating levels of $\mathrm{LDL}$, consistent with research findings.

"It has caused me the greatest trouble, and for ever causes me the greatest trouble, to perceive that unspeakably more depends upon what things are called, than on what they are."

Freidrich Nietzsche

\section{Background}

Atherosclerosis, the predominant cause of coronary artery disease, remains enigmatic. Despite best efforts, available therapies protect only $30-40 \%$ of individuals at risk, and no therapeutic cure is anticipated for those who currently suffer from the disease. Delayed progress concerning pharmaceutical treatment implies that atherosclerosis drug development is in jeopardy, raising concerns among experts [1].

This analysis addresses the logical properties of the hypothesis underlying our efforts, and reconsiders whether our perception of the disease is consistent with undisputed facts concerning coronary arteries in general and during disease in particular. A different perspective on the pathogenesis of atherosclerosis is proposed.

\section{Logical properties and factual consistency concerning a currently endorsed hypothesis relating to coronary atherosclerosis: common perception of coronary artery morphology}

A currently endorsed hypothesis is based on the following assumptions: (1) atherosclerosis is a systemic disease, initiated by endothelial dysfunction due to (2) inflammation and (3) high levels of LDL, (4) leading to lipid and macrophage deposition in the tunica intima from blood of the coronary lumen, and plaque formation (modified responseto-injury hypothesis) [2,3]. This perception is presented in mainstream scientific publications and in educational materials, whether printed or electronic. This hypothesis is typically accompanied by familiar schematics depicting the pathogenesis of coronary atherosclerosis and transition from a normal cardiac artery to a diseased state, e.g. Figure 1:

This perception of the mechanism of disease and similar schematics appear in wellrecognized scientific journals including Nature Medicine, Atherosclerosis, Thrombosis and Vascular Biology and etc. (e.g. [5]), and common educational materials such as the Britannica Online Encyclopaedia (Figure 2):

Therefore, this explanatory model concerning atherosclerosis, and accompanying schematics indistinguishable from that outlined above, are available in the majority of scientific publications and educational materials [2-6].

\section{Analysis of main assumptions of the currently endorsed hypothesis}

\section{Assumption: atherosclerosis is a systemic disease}

Factual contradiction Atherosclerosis never affects the entire arterial bed; it is exclusive to large muscular arteries, particularly coronary, and to a lesser extent to elastic arteries. Therefore, this systemic notion should be rejected on logical grounds; atherosclerosis is NOT a systemic disease. 


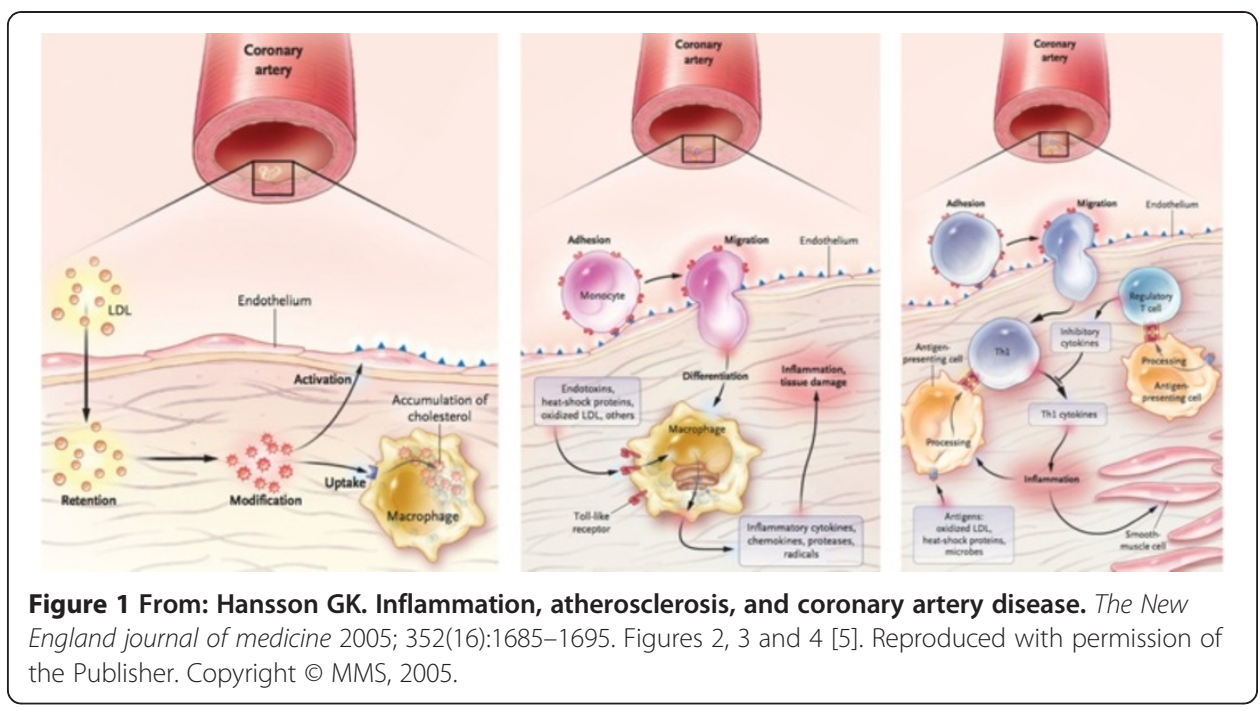

\section{Assumption: atherosclerosis is an inflammatory disease}

Varieties of microorganisms are present in advanced atherosclerotic lesions, for example in specimens removed during atherectomy [7]. Fabricant et al. induced visible atherosclerotic changes in chicken coronary arteries resembling that in humans, by infecting them with herpesvirus [8-10] and suggested the viral role in pathogenesis, a view shared by many scientists (for review see [11,12]). Mycoplasma pneumonia or Chlamydia pneumoniae infections alone [13] or together with influenza virus [14] have been proposed as contributory factors in the pathogenesis of atherosclerosis, and particularly by participation in obstruction of vasa vasorum [11]. However, these cases probably do not indicate the initiation of atherosclerosis, but are more likely to represent secondary infection of degenerating/ necrotic tissue. It should be emphasized that neither non-steroidal nor antibacterial antiinflammatory treatments alter the risk of coronary atherosclerosis [15-18]. Despite the

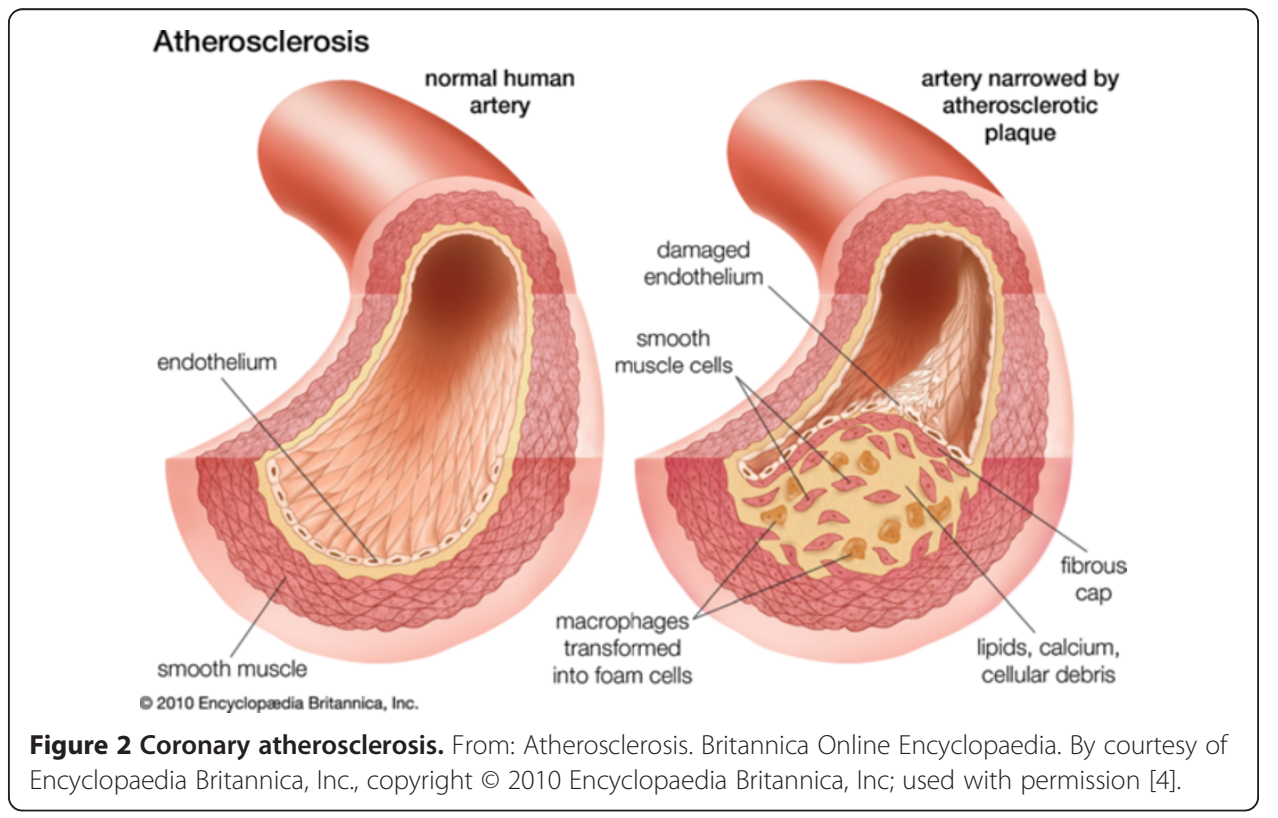


aforementioned studies [7-11,13,14], therefore, it can reasonably be claimed that no infectious cause of atherosclerosis has been demonstrated [19,20].

\section{Assumption: a high level of LDL initiates and is the main cause of atherosclerosis}

High levels of LDL are an important risk factor, and lowering LDL levels is the most significant pharmaceutical tool in coronary atherosclerosis prevention. However, the

statement that high levels of LDL are the main cause of coronary atherosclerosis is inconsistent with established medical concepts.

Inconsistency with the established concept in medicine "Indeed, proof that a given condition always precedes or accompanies a phenomenon does not warrant concluding with certainty that a given condition is the immediate cause of that phenomenon. It must still be established that when this condition is removed, the phenomenon will no longer appear. ..." Claude Bernard [21].

As has been emphasized by numerous scientists, multiple factors participate during disease development, and can affect the progression and severity of disease. However, only through distinguishing the cause from all contributing factors can an effective cure, leading to disease eradication, be achieved.

“... differentiating between cause and non-causative factors is essential. Elimination of the latter only ameliorates or reduces the incidence whereas elimination of the former eradicates the disease. Swamps are not a cause of malaria. Draining swamps may reduce the incidence of malaria but it is eradication of the malarial parasites that eliminates the disease. Reduction in incidence rather than elimination of the disease precludes a causal relationship." W. E. Stehbens [22].

Therefore, the fact that lowering LDL levels does not prevent cardiac events in 60-70\% of individuals at risk [23] contradicts the causative role of LDL. Unfortunately, it appears that the scientific and medical communities are focusing on and emphasizing biomarkers that can predict risk, without proof that these biomarkers cause the risk $[24,25]$.

Mechanisms of diseases constitute a new scientific field. However, although wellrecognized concepts are not always proved correct, the author believes that a new hypothesis should not contradict established concepts that have been proven as far as possible, without informed reasoning.

Factual discrepancies Lipid/macrophage pathogenesis of arteriosclerosis was suggested approximately one hundred years ago [26]. However, the hypothesis only gained proper attention during the 1970-80s, after a report concerning the Framingham Heart Study [27], culminating in joint NIH and American Heart Association publication of a Special Report [28], which was reprinted in all relevant journals [29-33]. The first Panel's Conclusion of the Report states: "Elevation of blood cholesterol levels is a major cause of coronary artery disease".

At approximately the same time, effective hypolipidemic drugs were developed and introduced to clinics, and the American Heart Association predicted that lowering blood cholesterol would almost eliminate the requirement for bypass surgery and 
eradicate coronary arteriosclerosis by the end of the $20^{\text {th }}$ century [5,34]. It is now known that HMG-CoA reductase inhibitors, cholesterol-lowering drugs known as "statins", are almost $100 \%$ effective in populations with high LDL-C levels, but normalizing LDL levels only reduces the risk of cardio-vascular diseases in this group by approximately $30-40 \%$ [23,35-38], and the total number of coronary interventions (bypass and stenting operations) has increased significantly [39]. However, individuals with normal LDL-C levels suffer from coronary atherosclerosis, and although at lower risk, this includes vegetarians [40]. Numerous studies have demonstrated that coronary atherosclerosis affects all eutherian animals with a body mass comparable to or larger than humans, regardless of diet specialization and LDL levels [41-45]. Surprisingly, in these mammals, lipid accumulations in arterial walls were more common in herbivores than carnivores $[43,46]$. The lack of association between total or LDL cholesterol and degree of atherosclerosis in unselected individuals was demonstrated by a study during the 1930s [47] and has since been noted by many others, notably by W. E. Stehbens [4854] and U. Ravnskov [55-59], and others, e.g. [60]. Therefore, the hypothesis that elevated blood cholesterol constitutes a major cause of coronary arteriosclerosis is questionable. Undoubtedly, high LDL levels are an important risk factor and a vital tool in CA prevention, but logically, it must be concluded that high LDL levels are not "a major cause" of coronary atherosclerosis.

\section{Assumption: lipids act and invade coronary tunica intima from the arterial lumen}

Factual discrepancies If high levels of LDL-C affect and invade arterial walls from the arterial lumen (Figure 1), then the initial and most pronounced lipid accumulation in the arterial tunica intima ought to be most proximal to the coronary blood flow, i.e. within inner layers of the tunica intima. However, detailed pathological studies concerning the early stages of human coronary atherosclerosis have demonstrated that the opposite is true, i.e. lipid deposits are initiated on outer layers of the coronary tunica intima [61,62], termed deeper musculoelastic layers (for morphological details and terms see [63]). A report published in 1968 described, although very briefly, the same morphological pattern during the early stages of human coronary atherosclerosis: initial lipid accumulation in the deepest intimal portion, followed by lipid deposition in the middle intimal zone [64]. This counterintuitive location of lipid depositions is very important for understanding the pathogenesis of coronary atherosclerosis, and I term this phenomenon the "outer lipid deposition paradox".

Nakashima et al. explained the outer lipid deposition paradox by demonstrating that accumulation of proteoglycan biglycan occurs predominantly in the outer layers of the tunica intima of normal and diseased individuals, i.e. in the same location as the initial accumulation of lipids. Furthermore, Nakashima et al. suggested that biglycan possesses specific binding properties for atherogenic lipoproteins. They noted that structural changes in biglycan could increase its binding properties, and suggested a possible source of biglycan expression in agreement with previous reports [65,66]. Noting some discrepancy in patterning, i.e. that lipids deposit eccentrically, whereas biglycan is localized concentrically [62], the authors elaborated these specifics in this and a later publication [67].

In addition to reporting significant findings on the precise location of lipid depositions during initiation of coronary atherosclerosis, this work univocally demonstrates that normal coronary tunica intima is not a single-layer endothelium covering a thin 


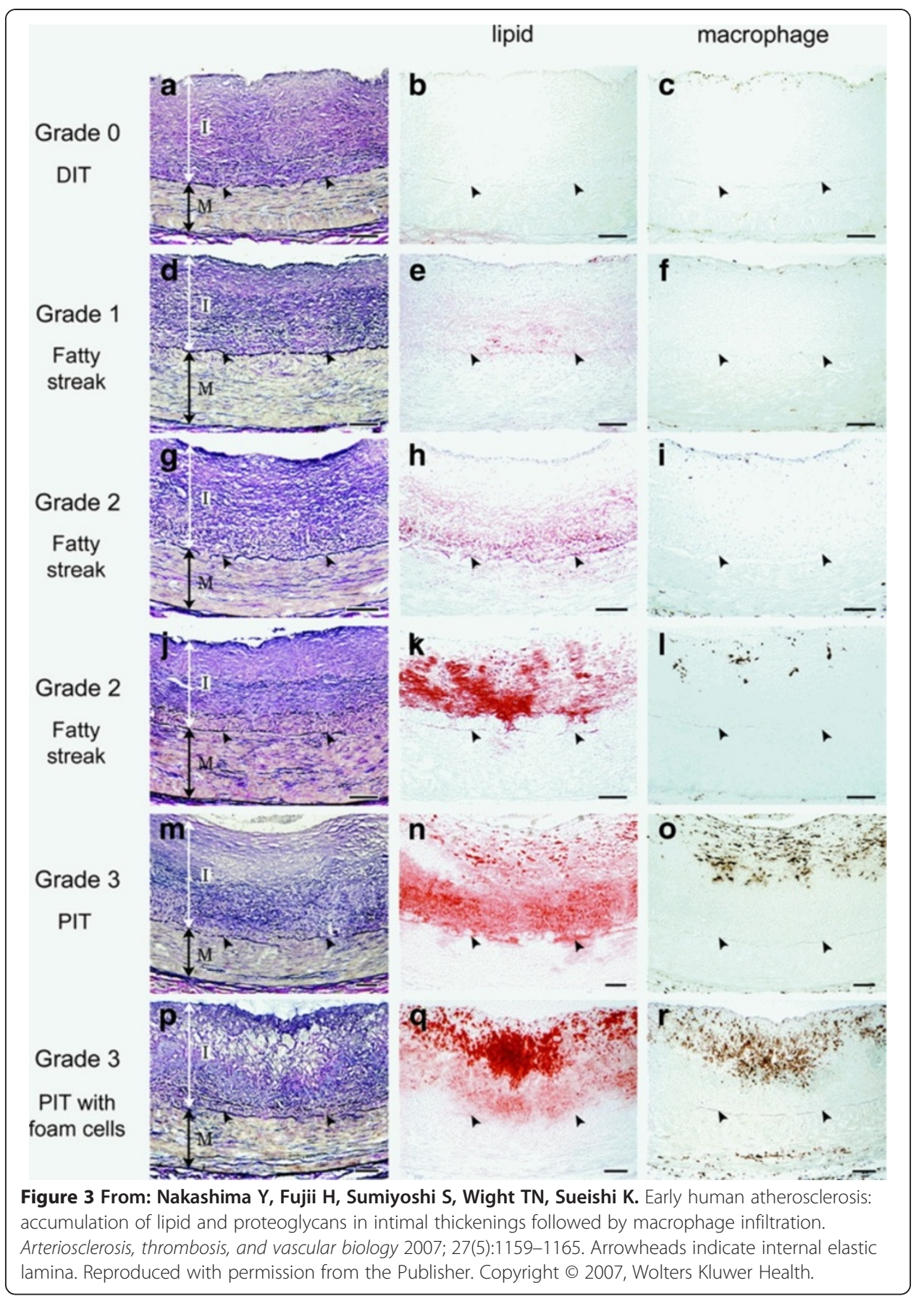

acellular compartment, as is commonly claimed in all mainstream scientific publications and educational materials (e.g. Figures 1 and 2), but a multi-layer cellular compartment where cells and matrix are arranged in a few dozen layers.

However, this is not a new discovery in coronary morphology. In 2002 Nakashima et al. published a complete morphological analysis concerning normal post-natal development of human coronary arteries, demonstrating that the epicardial coronary tunica intima invariably forms a multilayered cellular compartment, or diffuse intimal thickening (DIT) [68], known as normal arterial intimal hyperplasia [69]. Please note, this morphogenesis 

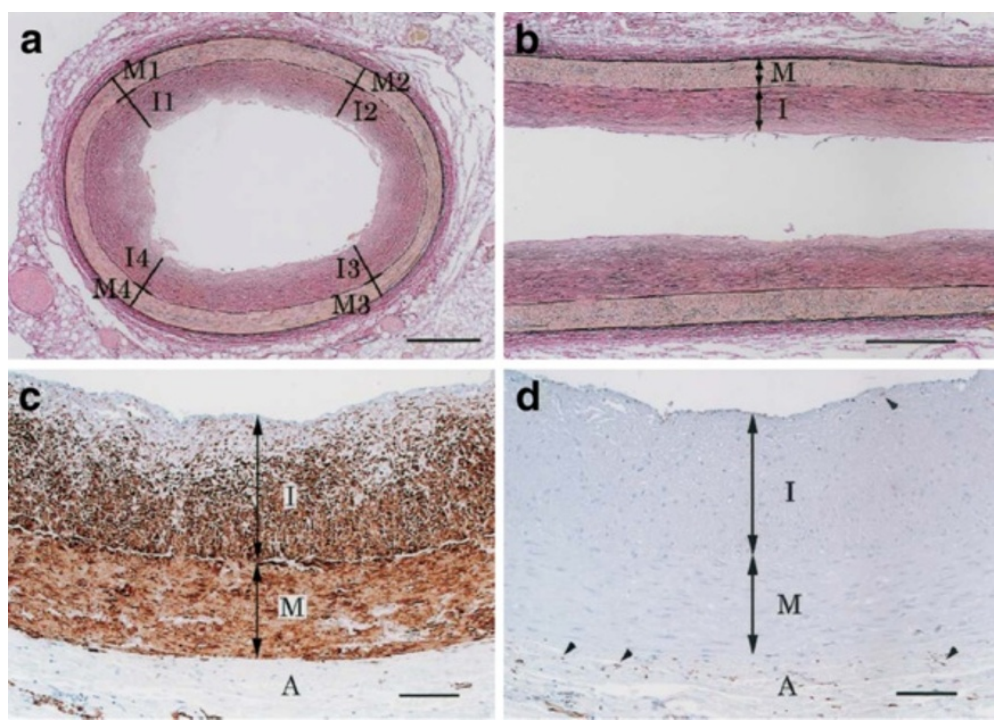

Figure 4 Structures and components of DIT in the proximal portion of the RCA in adults. $\mathbf{a}, \mathbf{b}-\mathrm{DIT}$ was demonstrated as a uniformly thickened inner layer (van Gieson). c - immunostain for alpha smooth muscle actin. Almost all cells in DIT were smooth muscle cells. $\mathbf{d}$ - immunostain for macrophage marker HAM56 at the same site as in c. Only a few intimal and several adventitial cells were positive (arrowheads). I - intima, M - media, A - adventitia. These microscopic images represent a normal right adult coronary artery in two intersecting planes. From: Nakashima Y, Chen YX, Kinukawa N, et al: Distributions of diffuse intimal thickening in human arteries: preferential expression in atherosclerosis-prone arteries from an early age. Virchows Arch 2002, 441:279-288. Used with permission from the publisher and authors. Copyright ( 2002, Springer.

necessarily occurs during early postnatal development in humans and is maintained throughout life.

From: Nakashima Y, Chen YX, Kinukawa N, et al: Distributions of diffuse intimal thickening in human arteries: preferential expression in atherosclerosis-prone arteries from an early age. Virchows Arch 2002, 441:279-288. Used with permission from the publisher and authors. Copyright () 2002, Springer.

From: Nakashima Y, Chen YX, Kinukawa N, et al: Distributions of diffuse intimal thickening in human arteries: preferential expression in atherosclerosis-prone arteries from an early age. Virchows Arch 2002, 441:279-288. Used with permission from the publisher and authors. Copyright $\odot$ 2002, Springer.

Nakashima et al. [68] credited all previous reports concerning DIT in normal human coronaries, beginning with a famous publication by Richard Thoma in 1883 [70] and concluding with modern papers, e.g. [71]. These references could be supplemented with dozens of others demonstrating that the formation of DIT in normal coronaries is universal in humans. One particular publication, written by Dr. Kapitoline Wolkoff in 1923 [72], was pioneering in relation to the detailed morphology of post-natal human coronary ontogenesis. In her observations, the intimal structures (in German "Bindegewebsschicht" and "Elastisch-hyperplastische Schicht") above a lamina elastica interna correspond to DIT in the modern literature $[63,67,68,73]$.

To my knowledge there are no definitive data concerning the number of cell layers forming DIT, which varies in formalin-fixed specimens owing to artery contraction in fixative [63]. In addition to individual variations, the latter could explain differences in DIT thickness in various reports, e.g. [68,72,74]. Therefore, it is difficult to determine an 

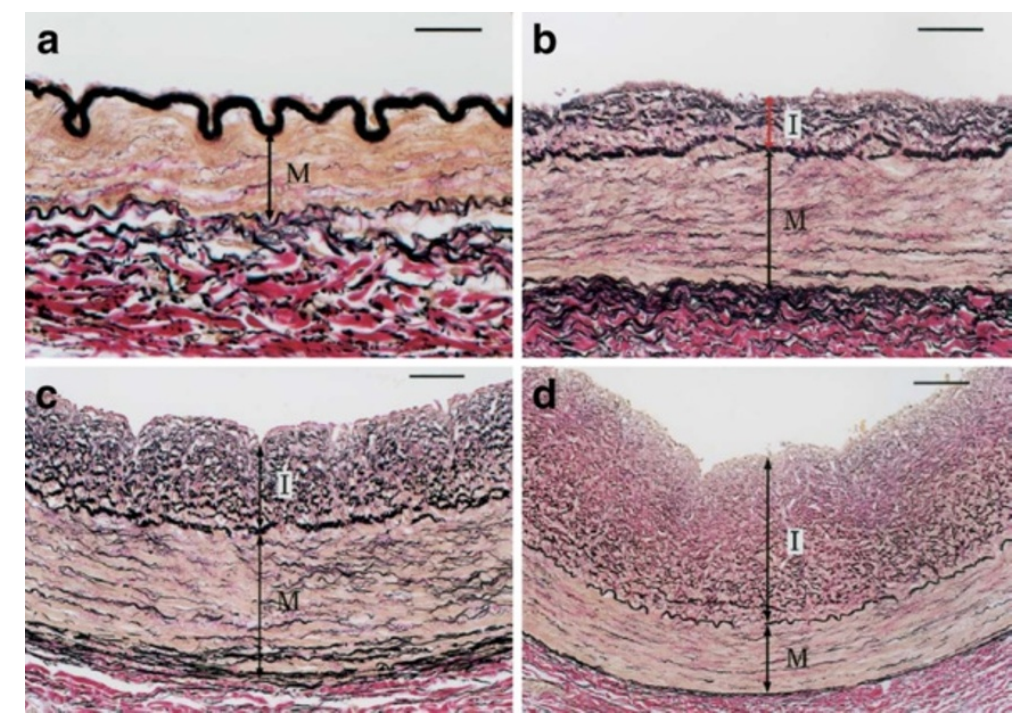

Figure 5 Diffuse intimal thickening (DIT) in proximal coronary arteries. a- Right coronary artery (RCA), 7-day-old female. $\mathbf{b}$ - Left anterior descending artery (LAD), 5-year-old female. c - LAD, 15-year-old female. d - LAD, 29-year-old female. Bars in a, b, c and d represent $25 \mu \mathrm{m}, 50 \mu \mathrm{m}, 50 \mu \mathrm{m}, 100 \mu \mathrm{m}$, respectively. I intima, $\mathrm{M}$ - media. These microscopic images represent normal morphological changes in coronary arteries from birth to adult (van Gieson stain). From: Nakashima Y, Chen YX, Kinukawa N, et al: Distributions of diffuse intimal thickening in human arteries: preferential expression in atherosclerosis-prone arteries from an early age. Virchows Arch 2002, 441:279-288. Used with permission from the publisher and authors.

Copyright @ 2002, Springer

exact number of cell layers in DIT, although extrapolating from all available reports it can be approximated as between $20-25$ and 35-50 cell layers. Coronary artery DIT has been found in all studies concerning vertebrates with a body mass similar to or larger than humans (for review see [69]), and taxonomy-wise starting with fishes [75]. Unfortunately, these fundamental facts have not been widely appreciated during medical research and education, which commonly operates on the assumption that normal coronary arterial tunica intima is always an "ideal" single-layer endothelium covering an acellular compartment [4-6,76], or denying the presence of coronary DIT in animals [77].

\section{Discussion}

When considering coronary atherosclerosis, we inevitably focus on atherosclerotic plaques, their vulnerability and rupture, lipid and necrotic core, fibrous cap and thickness, as these features determine morbidity and mortality. However, these are features of advanced stages of the disease, and such lesions [78-80] are extremely resistant to therapeutics. Progress in plaque stabilization and regression has been reported, but the probability that these patients will require coronary intervention is very high (for review see [81]). This analysis concerns initiation and early stages of CA, which should be more receptive to therapeutics and are potentially reversible. In addition, initial tissue transformations are more informative in terms of elucidating mechanisms of disease, as later pathological formations (e.g. mature plaque) include significant secondary lesions, which could mask crucial features of disease pathogenesis.

An important part of this analysis is devoted to the consistency of the hypothesis that guides our efforts to understand coronary atherosclerosis, relating to facts concerning normal coronary morphology and the diseased state. As demonstrated above, the 
morphology of human coronary arteries is not what is commonly claimed in analyses relating to coronary atherosclerosis, which underlies approaches to finding a cure. Unfortunately, this inaccurate perception of coronary artery morphology has led to hypotheses that imply that DIT is a dimensionally insignificant compartment, e.g. [4-6]. Furthermore, such depiction appears in articles that include micrographs of coronary artery histological slides that demonstrate the real ratio between coronary artery coats, e.g. [82]

Therefore, although the coronary tunica intima is a multi-layered cellular compartment equal to or thicker than the tunica media [62,63,67,68,70,72,83-85], there is a common perception that the human coronary tunica intima is a one-cell layer covering a thin matrix layer $[4-6,82,86]$. Since this perception is very persistent in scientific publications and educational materials, I believe it is worthwhile to look for a reason for this misinterpretation.

Custom replies such as: "it is just an unimportant visual (or verbal) schematic, but the foundation of the hypothesis is correct" are not convincing. A schematic that presents a hypothesis is the essence of the hypothesis. Therefore, if the schematic is incorrect, the hypothesis must be incorrect too.

Incorrect presentation of human coronary morphology (depicting the tunica intima as one cell layer covering a thin matrix layer) has several negative consequences, but the most crucial is that such misperception cannot incorporate the outer lipid deposition paradox. Even when early intimal lipid deposition is mentioned, incorrect presentation of tunica intima morphology as a one cell layer structure covering a thin matrix layer does not make outer lipid deposition surprising (paradoxical) and prevents a hypothesis from using this observation as a tool during analysis of the disease pathogenesis [82].

One plausible explanation for this oversight could be that medical scientists in mainstream research are not aware of the exact coronary artery morphology or consider it an insignificant detail. This is probably a reflection of how coronary histology is taught to medical students. Any standard textbook of histology, e.g. [87-89], and most monographs concerning coronary disease, e.g. [90-93], present coronary morphology in this way. The famous "Color Atlas of Cytology, Histology, and Microscopic Anatomy" used by medical students and published by Wolfgang Kuehnel [94], which was translated into all Western languages, does not include coronary artery morphology, leaving readers with the illusion that it has the same morphology as any artery of this caliber. At best, some textbooks comment briefly that the intima of elastic arteries may be thicker $[95,96]$ or that the intima of coronary arteries demonstrates the greatest age-related changes [97,98], still stressing the single-cell layer intimal design. An example of such misrepresentation appears in the very popular Medscape website (a part of WebMD), which advertises itself as: "Medscape from WebMD offers specialists, primary care physicians, and other health professionals the Web's most robust and integrated medical information and educational tools" [99]. In its recently updated article relating to coronary artery atherosclerosis, Medscape states: "The healthy epicardial coronary artery consists of the following 3 layers: Intima, Media, Adventitia. The intima is an inner monolayer of endothelial cells lining the lumen; it is bound on the outside by internal elastic lamina, a fenestrated sheet of elastin fibers. The thin subendothelial space in between contains thin elastin and collagen fibers along with a few smooth muscle cells (SMCs)" [100]. The few modern textbooks presenting correct information, e.g. "Histology for Pathologist" [101] and "Vascular Pathology" [102], have not changed this 
common perception. Regardless of whether the above explanation is correct or not, this misperception of coronary artery design persists in research and education.

Failure to incorporate facts concerning coronary artery design into hypotheses relating to the mechanism(s) of coronary atherosclerosis is worrying. The accepted hypothesis describes lipid invasion into the coronary DIT from the arterial lumen [5,6,82,86,103,104]. The accepted vector and topology of events is the core of the hypothesis and the assumed mechanism of the disease: "Lipids enter the arterial wall as compounds with protein fractions of blood plasma directly from arterial lumen" [105]. This pathway is univocally incorporated in the currently endorsed hypothesis and all offshoot models. Logically, from these models, initial lipid deposition in the tunica intima should be more proximal to the lumen. However, it has been demonstrated that lipid accumulation appears not in the inner layers of DIT, which are proximal to the lumen, but in the distant outer layers $[61,62,64,67]$. Obviously, to reach an outer intimal layer, lipids are required to diffuse through numerous cell layers and a significant amount of matrix situated between the intimal cells. However, in diffusion or "filtration pressure" [106] models, the highest lipid accumulation must be most proximal to a lumen, diminishing proportionally to intimal depth, comparable to patterns of lipid accumulation in tunica intima of non-diseased human aortas of individuals aged 6-15 years [107]. Therefore, why does lipid accumulation in coronary atherosclerosis start in the deep layers of DIT, just above the internal elastic lamina, distant from the lumen? To explain this contradiction, the conventional hypothesis has to relate to certain conditions under which this puzzling pattern could be theoretically possible: e.g. co-localization of proteoglycan biglycan (which has a high binding capacity for lipoproteins) in the outer layer of DIT $[62,67,82]$. However, findings concerning biglycan location [62,67] could explain retention but not penetration, and even the former can only be explained with reservations: biglycan is expressed in several tissues of the body, so why is the outer DIT of coronary the target? Is this complicated model the only explanation?

Details of coronary artery structure are critically important for this analysis. Therefore, it is necessary to enumerate undisputed facts concerning coronary artery morphology. The human heart has coronary arteries in which a single-cell layer of tunica intima differentiates early in life to form DIT, and then continues to self-renew in a controlled manner throughout life in a majority of the population. When normal DIT becomes diseased, it is difficult to distinguish early pathology morphologically from the norm [108,109], and sometimes this is the case with advanced stages (post-transplant coronary atherosclerosis) [76]. Normal DIT, or normal intimal hyperplasia, is so striking in its resemblance to diseased hyperplasia that the former is known as "benign intimal hyperplasia" [110-112].

It is important to highlight that normal human coronary tunica intima, evolving from one cell-layer after birth to DIT in adults, is always the avascular compartment and remains avascular in the vast majority of hearts throughout life. Several studies have investigated this topic thoroughly and concluded that coronary tunica intima receives oxygen and nutrients through diffusion from the arterial lumen [106,113-116]; a previous suggestion that nutrients from vasa vasorum can meaningfully contribute to coronary tunica intima nourishment [117] was never confirmed. Past findings concerning the vasculature in normal coronary intima [118], later reprinted in [119], were attributed to high pressure of injected dye (ten times higher than normal) [106]. Therefore, when DIT attains thickness of up to ten cell layers (at approximately five years old), inner and outer 
compartments of tunica intima are exposed to various concentrations of blood constituents, as diffusion is inversely proportional to the square of the distance (i.e. DIT thickness). When this distance is increased, as happens in adult coronary DIT, it must be assumed that contact of outer intimal layers with certain blood constituents would be significantly minimized, if not completely diminished. Therefore, for adult or aged-thickened [120] and diseased-thickened coronary tunica intima, diffusion deficit of the outer intimal layers can be assumed, similar to the model of Wolinsky and Glagov, known as "critical depth" of avascular media or "rule 29" [121].

As aforementioned, before plaque formation occurs, diseased DIT, or pathologic intimal thickening (PIT), is microscopically indistinguishable from normal DIT. However, there is one characteristic that distinguishes diseased coronary DIT from normal DIT: pathological DIT (PIT), even during the beginning of the disease, is always vascularized [106,113-115,122]. This neovascularization, originating from adventitial vasa vasorum $[123,124]$, is observed prior to the appearance of any atherosclerotic features except an increased dimension of DIT [125]. This neovascularization pattern is common in all diseased arterial DIT [126]. Contrary to a previous report concerning coronary atherosclerosis $[118,119]$, in contemporary publications luminal neovascularization, although reported in one study, was found to be negligible: vasculature originating from adventitial vasa vasorum exceeds luminal vessels 28 times [127]. This intimal neovasculature exclusively terminates in the outer tunica intima of the atherosclerotic human coronary artery, just above the internal elastic lamina, [113,116,123,127-131]. A comparable pattern of coronary outer tunica intima neovascularization has been demonstrated in a porcine model of coronary atherosclerosis [132].

Now, we shall enumerate the facts:

(1) Normal coronary DIT is an avascular compartment, receiving blood constituents through diffusion from the arterial lumen;

(2) Normal outer DIT is the most distant compartment from the arterial lumen and adventitial vasa vasorum. Therefore, the probability of diffusion to this depth of some blood constituents including LDL-C particles is very low;

(3) The outer avascular tunica intima of normal and atherosclerotic coronary is always reached by proteoglycan biglycan, which has a high capacity for selective binding of lipoproteins;

(4) In normal coronary artery, biglycan of the outer DIT does not have direct contact with blood, and interaction with LDL-C is prevented by diffusion distance and the properties of this molecule $(20 \mathrm{~nm})$;

(5) In coronary atherosclerosis, the outer layers of DIT become exclusively neovascularized, and biglycan comes into direct contact with blood lipoproteins.

If the above statements stand, a simple conclusion can be reached: in coronary atherosclerosis, biglycan of the outer DIT should extract and retain LDL-C particles from newly formed capillary beds, which are known to be very permeable $[133,134]$. This mechanism does not require any conditioning or complicated explanatory pathways. Furthermore, as we know from observations, lipid accumulation during early stages of coronary atherosclerosis always begins in the outer layers of the coronary DIT $[61,62,64,67]$. 
The assumption that neovascularization of the outer tunica intima is the first step in pathogenesis results in a hypothesis that produces the simplest explanations: (1) an initial deep localization of lipid deposition in the tunica intima, (2) a certain probability of coronary lipid deposition and atherosclerosis development when blood LDL levels are normal if pathological neovascularization has occurred, owing to LDL-C accessibility for contact with previously avascular structures (biglycan, which has affinity to LDL-C, and should extract it regardless of LDL-C levels); (3) more probable lipid deposition and disease contraction at high blood LDL levels; (4) probability of coronary atherosclerosis development after high LDL levels are lowered through the use of drugs, as neovascularization has already occurred and LDL-C particles appear in direct contact with previously avascular structures (biglycan, which has affinity to LDL-C and should extract it regardless LDL-C levels). At this point in the analysis, neovascularization of the coronary tunica intima appears as a cause of coronary atherosclerosis. Therefore, it logically follows that since the presence of LDL-C in plasma is a fundamental metabolic requirement for humans [135], theoretically there is no "safe LDL-C level" that would be $100 \%$ certain to prevent coronary atherosclerosis if intimal neovascularization has already occurred.

Therefore, the model predicts that if the coronary intima became vascularized, lipoproteins would be extracted and retained by intimal proteoglycan biglycan even if blood LDL levels were normal. However, lipoprotein extraction and deposition will be faster if LDL levels are high. These model predictions have been confirmed by clinical observations. Therefore, contrary to the accepted model, the author's hypothesis suggests a different cause of the disease, and the opposite route for invasion of atherogeneic lipoproteins into the coronary tunica intima.

It is plausible that other intimal components, which were expressed and stored in the avascular environment, would interact with blood lipoproteins in the neovascularized environment. Hypothetical affinity to and binding of lipoproteins could be the result of LDL-C availability and matrix modifications under oxygenized conditions [136].

The author's hypothesis does not refute the contribution of lipoprotein deposition from the arterial lumen. It is known that such deposition occurs in normal aorta, although resulting in a different pattern [107]. However, in the author's model, lipoprotein deposition from the arterial lumen becomes irrelevant. Let us just compare the probability of two events occurring (i.e. lipid deposition via two pathways): (1) lipoproteins travel from the arterial lumen through the endothelium and multiple cell/matrix layers to be deposited in the outer DIT; (2) lipoproteins exude into the outer DIT from newly formed capillary beds, which terminate directly into the outer DIT and are very permeable [133,134]. The greater likelihood of the second model is obvious. The same logic could be applied to infer a route of monocyte infiltration into the coronary intima.

In previous publications, a similar mechanism was suggested to contribute to progression of already formed coronary plaques and inflammation in advanced human coronary atherosclerosis [137-140]. However, all prior analyses stop short of suggesting that neovascularization of the outer tunica intima is the cause of the disease.

This suggested mechanism of pathology is not unique. The identical mechanism, involving neovascularization of a normally avascular tissue compartment, followed by lipoprotein deposition, is well known. Consider corneal lipid keratopathy. The cornea is normally an avascular compartment [141,142]. More than 50 years ago, Cogan and 
Kuwabara described cornea lipid keratopathy, consisting of lipid deposition followed by fatty plaque formation, as occurring only in corneal areas that have been previously neovascularized [143]. Furthermore, the authors pointed to morphological similarities between cornea lipid plaques and those in atherosclerosis, and suggested common pathogenesis [143]. In succeeding years, numerous reports reaffirmed a causal role of neovascularization in corneal lipid deposition and hence the main treatment modality has become the inhibition of neovascularization [141,142,144-153]. In addition, there is only a single clinical observation of lipid keratopathy without prior neovascularization [154], and a single experimental study that disputes the causal role of neovascularization in corneal lipid deposition [155]. Furthermore, it has been noted that a role of inflammation during this pathogenesis is limited to the induction of angiogenesis [152]. Lipoprotein levels in the aqueous humor are thought to be close to those in blood [156-161]. It is important to note that although the corneal substantia propria is separated from aqueous humor by only one cell layer of descemet epithelium, lipid depositions have never been observed prior to corneal neovascularization (except the one report mentioned above [154]). This strongly favors the model of lipids exuding from permeable neovasculature into the cornea proper, rather than a diffusion model.

The fact that a similar sequence of events that includes lipid deposition underlines pathogenesis of the unrelated corneal disease reinforces the suggested new hypothesis concerning mechanisms of coronary atherosclerosis.

Why does arterial tunica intima become neovascularized in the first place?

Early during life the tunica intima of human coronary arteries differentiates from a single-layer cell compartment into a multi-layer cellular structure (i.e. DIT) through proliferation of residual and medial cells, and probably through participation of bloodborn cells. Intimal proliferation with increasing numbers of cells continues until approximately 30 years of age $[68,72]$ and then maintains self-renewal in a controlled manner throughout life. The mechanisms that initiate this morphogenesis and control it later during life are unknown, but it can be concluded that cells in the coronary tunica intima possess inherently high proliferative capacity. During normal growth transformations the coronary DIT remains avascular, so its dimension (thickness) allows all intimal cells to receive sufficient oxygen and nutrients through diffusion from the arterial lumen.

If we were to choose one feature that would universally reflect the reaction of the arterial tunica intima, and particularly the coronary intima, to a variety of stimuli, injuring factors, and interventions in clinics and experiments, the answer is undoubted - it is intimal cell proliferation. Regardless of the nature and magnitude of stimuli/ insults, cells that appear in the arterial intimal compartment (normal or artificial, e.g. [162-167]), always proliferate in response. Furthermore, it is known that the arterial tunica intima can develop two normal variant phenotypes: a one-cell lining and a multi-layered cellular compartment, i.e. DIT. The first phenotype is maintained in all small and most medium caliber arteries, but certain arterial segments (e.g. coronary) normally evolve into the second phenotype. Each intimal type can be maintained as stable phenotypes or produce excessive intimal cell proliferation. Multiple observations have demonstrated that cells participating in this morphogenesis can be of different origins. As to regulations directing normal and pathological morphogenesis, a shear stress 
was suggested as the major factor [168-178]. In addition, I hypothesized that the arterial blood-tissue interface itself (as a topological entity) contributes to this morphogenesis, and the enhanced proliferative capacity of the arterial intima is a reflection of phenotype selection [69,179] (though these statements do not suggest mechanisms of regulation). All observations demonstrate that intimal proliferation can be induced by a variety of stimuli and insults that are different in nature and magnitude, which suggests that these stimuli and insults act as non-specific factors triggering preexisting regulation for proliferative morphogenesis. The ability of the arterial intima, and particularly coronary intima, to slip into proliferative morphogenesis was described as a genetic predisposition, which could manifest in "a hyperplastic vasculomyopathy" [180].

Therefore, cells in the coronary tunica intima respond by proliferating to any stimuli, exogenous or endogenous. An increase in cell numbers inevitably expands intimal thickness, which occurs with aging $[119,181]$. Expanded intimal thickness impairs diffusion of oxygen, as diffusion is inversely proportional to the square of the distance. Insufficient oxygen diffusion would inevitably result in hypoxia, specifically of cells in the outer DIT, because this tissue compartment is the most distant from the lumen and adventitial vasa vasorum [182].

What would happen when the coronary DIT becomes larger owing to cell proliferation or excessive matrix deposition (I did not mention a possible participation of intimal matrix before because there are few facts describing this pathway)? A straightforward answer was given by Gladstone Osborn: "When the intima of the coronary artery exceeds a certain thickness parts must either die or develop secondary blood supply" [183]. Since tissue hypoxia is a known inducer of angiogenesis and pathological neovascularization $[184,185]$, neovascularization of the outer compartment of disease coronary DIT from adventitial vasa vasorum must follow coronary DIT expansion. The author agrees with Geiringer's assertion that ". . intimal vascularization is a function of intimal thickness and not of atherosclerosis" [105]. Furthermore, the author's deduction from the above is that intimal proliferation/thickening and neovascularization are the causes of coronary atherosclerosis.

Therefore, it is hypothesized herein that proliferation of intimal cells initiates atherosclerosis. This is not a new model. This mechanism was suggested some time ago, although omitting subsequent neovascularization of coronary DIT [186-192]. However, the viewpoint that intimal cell proliferation is the beginning of atherosclerosis [186-192] was superseded by the currently endorsed hypothesis, which asserts that arterial intimal proliferation is an event secondary to lipid/macrophage penetration and inflammation $[2,3,5,6,193]$. Reflecting on the convenient hypothesis, the current classification of atherosclerosis excludes a variety of arterial pathologies characterized by intimal cell proliferation [194]. However, the currently endorsed hypothesis is based on an incorrect perception of coronary artery morphology. DIT enlargement and subsequent neovascularization were not recognized as initiators of the disease, and this view does not acknowledge outer lipid deposition as paradoxical. The currently endorsed model, based on invasion of lipoproteins from the coronary lumen, is very unlikely in the light of preceding DIT neovascularization. In the model outlined herein, neovascularization of the deep layers of DIT from the vasa vasorum makes initial outer intimal lipid deposition logical not paradoxical. Neovascularization of the previously avascular deep layers of coronary DIT, resulting in availability of blood lipoproteins to be extracted and retained by the DIT 
matrix, explains controversies regarding normal LDL-C levels (spontaneous or drugmodulated) and risks for coronary atherosclerosis.

The suggested hypothesis can be presented in the following schematics (Figure 6):

\section{Summary}

(1) A hypotheses underlining our efforts to approach coronary atherosclerosis must be consistent with undisputed facts concerning the subject. Furthermore, a hypothesis should incorporate logical evaluation, and not contradict established and proven concepts in biology and medicine without well-grounded reasons.

(2) Atherosclerosis occurs in arteries with normal DIT, while sparing the rest of arterial bed. However, while normal DIT exists in numerous arteries [120,194], some of these are never affected by atherosclerosis; coronary arteries are almost always the target. On logical grounds, an arterial disease that never affects some arteries but usually affects certain others is not systemic.

(3) Coronary atherosclerosis is not an inflammatory disease, as multiple clinical trials demonstrate no correlation between anti-inflammatory therapies and risk of disease.

(4) High LDL levels are not a fundamental cause of coronary atherosclerosis, as lowering such levels protects only $30-40 \%$ of those at risk. Furthermore, humans and animals with normal LDL levels can suffer from coronary atherosclerosis.

(5) Neovascularization of the normally avascular DIT is the obligatory condition for coronary atherosclerosis development. This neovascularization originates from adventitial vasa vasorum and vascularizes the outer part of the coronary DIT, where LDL deposition initially occurs.

(6) It is suggested that excessive cell replication in DIT is a cause of DIT enlargement. Participation of enhanced matrix deposition is also plausible. An increase in DIT dimension impairs nutrient diffusion from the coronary lumen, causing ischemia of cells in the outer part of coronary DIT.

(7) Ischemia of the outer DIT induces angiogenesis and neovascularization from adventitial vasa vasorum. The newly formed vascular bed terminates in the outer part of the coronary DIT, above the internal elastic membrane, and consists of permeable vasculature.

(8) The outer part of the coronary DIT is rich in proteoglycan biglycan, which has a high binding capacity for LDL-C. While in avascular DIT, biglycan has very limited access to LDL-C due to diffusion distance and LDL-C properties; after neovascularization of the outer DIT, proteoglycan biglycan acquires access to LDL-C particles, and extracts and retains them.

(9) Initial lipoprotein influx and deposition occurs from the neovasculature originating from adventitial vasa vasorum - and not from the arterial lumen.

(10) Although lipoprotein deposition in the outer part of the coronary DIT is the earliest pathological manifestation of coronary atherosclerosis, intimal neovascularization from adventitial vasa vasorum must precede it.

Therefore, in the coronary artery tunica intima, a previously avascular tissue compartment becomes vascularized. All other tissue compartments are developed (both phylogenetically and ontogenetically) with constant exposure to capillary bed and 


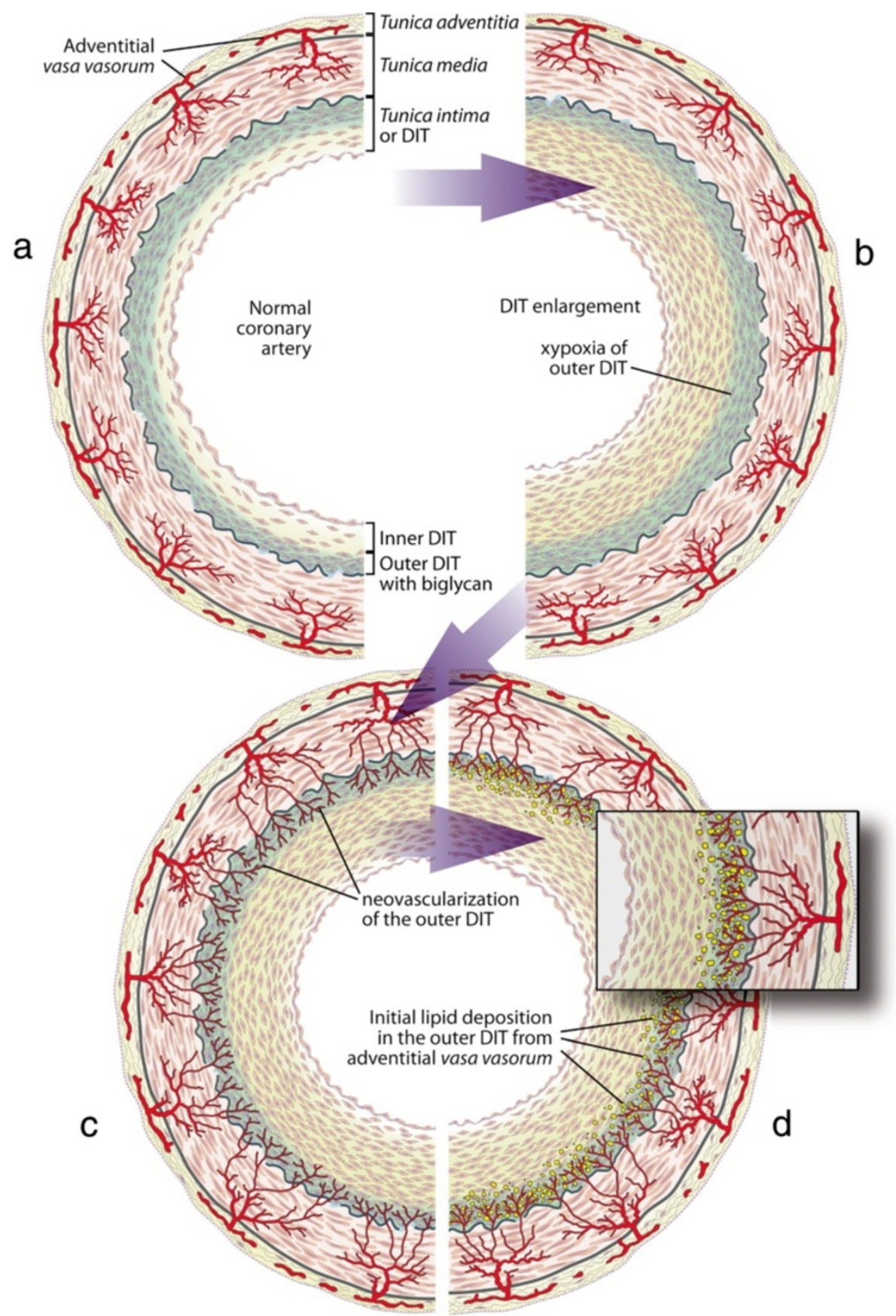

Figure $\mathbf{6}$ Schematic representations of the mechanism of CA. a - normal coronary artery. Coronary tunica intima forms DIT with biglycan accumulations in the outer DIT, which is most distant from the arterial lumen. $\mathbf{b}$ - DIT enlarged by cell proliferation and matrix production. Cells in the outer DIT underwent hypoxia due to increased diffusion distance. $\mathbf{c}$ - neovascularization of the outer DIT from adventitial vasa vasorum. Newly formed vessels are highly permeable. $\mathbf{d}$ - biglycan of the outer DIT comes in direct contact with blood LDL-C, which facilitates binding, retention and deposition of LDL-C in outer DIT, while inner DIT is free from lipoproteins. This schematic stage $\mathbf{d}$ corresponds to fatty streak Grade 1 and Grade 2 in the Nakashima et al. study [62]. Please note, in the schematic of a normal coronary artery (a), the number of DIT layers shown is less than my estimation in the text. This alteration was necessary to present half of the arterial circumference and emphasize DIT enlargement at the same time in the picture. 
blood, therefore their tissue components were selected not to bind LDL. This is why atherosclerosis is mostly limited to the coronary arteries. To my knowledge the only other example - the avascular cornea - shows the same lipid deposition after neovascularization.

The author does not claim that his hypothesis offers an immediate solution. Intimal cell proliferation, producing DIT and its later expansion, is cell hyperplasia, meaning that newly arrived cells are similar to normal residual cells, making systemic targeting very difficult. While the author strongly believes that intimal neovascularization is the crucial step in the pathogenesis of coronary atherosclerosis, there are obvious concerns about angiogenesis inhibition in a heart with an already jeopardized myocardial blood supply. The author does not intend to suggest an immediate solution. The goal was to evaluate the hypothesis and the perceptions that we exercise in approaching coronary atherosclerosis logically and factually, and to offer a more coherent model. Furthermore, the intent was to underline paradoxical observations that could provide new insights into mechanisms of the disease. Atherosclerotic plaque growth and rupture are not paradoxical but anticipated events. In contrast, initial lipid deposition in outer layers of DIT with no deposition in inner layers is a paradoxical observation, and requires an explanatory model that differs from the accepted one. However, to recognize the paradox, correct perception of the coronary artery structure, where pathology occurs, must not be distorted by incorrect illustrations and verbal descriptions. When we name or depict things incorrectly, often just for nosological reasons, the incorrect perception of events may persist in spite of growing knowledge, impeding our attempts to discover the truth.

Conflict of interest

The author declares that he has no competing interests.

Author's contribution

VMS conducted all the work involved in preparing and writing this paper.

\section{Acknowledgements}

The author thanks Michael Subotin for numerous translations from German and for constructive discussions on logic of the argument. I am very grateful to Paul S. Agutter, whose support encourages the author to continue this analysis.

Received: 27 February 2012 Accepted: 18 March 2012

Published: 10 April 2012

References

1. Fryburg DA, Vassileva MT: Atherosclerosis drug development in jeopardy: the need for predictive biomarkers of treatment response. Sci Transl Med 2011, 3:1-5. 72cm76.

2. Moore S: Vascular System. A. Blood vessels and lymphatics. In In Anderson's Pathology. Volume 1. 10th edition. Edited by Damjanov I, Linder J, Louis St, Mosby Mo. 1996:1397-1420.

Ross R: he pathogenesis of atherosclerosis: a perspective for the 1990s. Nature 1993, 362:801-809.

Britannica E: Atherosclerosis.: In Britannica Online Encyclopaedia Encyclopaedia Britannica, Inc; 2010

Hansson GK: Inflammation, atherosclerosis, and coronary artery disease. N Engl I Med 2005, 352:1685-1695

. Dzau VJ, Braun-DullaeuS RC, Sedding DG: Vascular proliferation and atherosclerosis: new perspectives and therapeutic strategies. Nat Med 2002, 8:1249-1256.

7. Ott SJ, El Mokhtari NE, Musfeldt M, et al: Detection of diverse bacterial signatures in atherosclerotic lesions of patients with coronary heart disease. Circulation 2006, 113:929-937.

8. Fabricant CG, Fabricant J: Atherosclerosis induced by infection with Marek's disease herpesvirus in chickens. Am Heart J 1999, 138:S465-468.

9. Fabricant CG, Fabricant J, Litrenta MM, et al: Virus-induced atherosclerosis. J Exp Med 1978, 148:335-340.

10. Minick CR, Fabricant CG, Fabricant J, et al: Atheroarteriosclerosis induced by infection with a herpesvirus. Am J Pathol 1979, 96:673-706. 
11. Ravnskov U, McCully KS: Review and hypothesis: vulnerable plaque formation from obstruction of Vasa vasorum by homocysteinylated and oxidized lipoprotein aggregates complexed with microbial remnants and LDL autoantibodies. Ann Clin Lab Sci 2009, 39:3-16.

12. Popovic M, Smiljanic K, Dobutovic B, et al: Human cytomegalovirus infection and atherothrombosis. J Thromb Thrombolysis 2012, 33:160-172.

13. Damy SB, Higuchi ML, Timenetsky J, et al: Mycoplasma pneumoniae and/or Chlamydophila pneumoniae inoculation causing different aggravations in cholesterol-induced atherosclerosis in apoE KO male mice. BMC Microbiol 2009, 9:194

14. Birck MM, Pesonen $E$, Odermarsky $M$, et al: Infection-induced coronary dysfunction and systemic inflammation in piglets are dampened in hypercholesterolemic milieu. Am J Physiol Heart Circ Physiol 2011, 300:H1595-1601.

15. Matchaba P, Gitton X, Krammer G, et al: Cardiovascular safety of lumiracoxib: a meta-analysis of all randomized controlled trials $>$ or $=1$ week and up to 1 year in duration of patients with osteoarthritis and rheumatoid arthritis. Clin Ther 2005, 27:1196-1214.

16. Cannon CP, Braunwald $\mathrm{E}, \mathrm{McCabe} \mathrm{CH}$, et al: Antibiotic treatment of Chlamydia pneumoniae after acute coronary syndrome. N Engl I Med 2005, 352:1646-1654.

17. Grayston JT, Kronmal RA, Jackson LA, et al: Azithromycin for the secondary prevention of coronary events. N Engl J Med 2005, 352:1637-1645.

18. Andraws R, Berger JS, Brown DL: Effects of antibiotic therapy on outcomes of patients with coronary artery disease: a meta-analysis of randomized controlled trials. JAMA 2005, 293:2641-2647.

19. Nicolle LE: Chlamydia pneumoniae and atherosclerosis: the end? Can I Infect Dis Med Microbiol 2005, 16:267-268.

20. Watson C, Alp NJ: Role of Chlamydia pneumoniae in atherosclerosis. Clin Sci (Lond) 2008, 114:509-531.

21. Bernard C: An introduction to the study of experimental medicine. New York: Henry Schuman, Inc.; 1949.

22. Stehbens WE: The concept of cause in disease. J Chronic Dis 1985, 38:947-950.

23. Libby P: The forgotten majority: unfinished business in cardiovascular risk reduction. J Am Coll Cardiol 2005, 46:1225-1228.

24. Lands B: Planning primary prevention of coronary disease. Curr Atheroscler Rep 2009, 11:272-280.

25. Libby P, Ridker PM, Hansson GK: Progress and challenges in translating the biology of atherosclerosis. Nature 2011, 473:317-325.

26. Anitschkow N: Über die experimentelle atherosklerose der herzklappen. Virchows Arch 1915, 220:233-256

27. Kannel WB, Castelli WP, Gordon T: Cholesterol in the prediction of atherosclerotic disease. New perspectives based on the Framingham study. Ann Intern Med 1979, 90:85-91.

28. Anonimus: Consensus conference. Lowering blood cholesterol to prevent heart disease. JAMA 1985, 253:2080-2086

29. Anonimus: Lowering blood cholesterol to prevent heart disease. NIH consensus development conference statement. Nutr Rev 1985, 43:283-291.

30. Anonimus: NIH Consensus Development Conference. Lowering blood cholesterol to prevent heart disease. Wis Med J 1985, 84:18-19.

31. Ernst ND: NIH consensus development conference on lowering blood cholesterol to prevent heart disease: implications for dietitians. J Am Diet Assoc 1985, 85:586-588.

32. Anonimus: Lowering blood cholesterol to prevent heart disease. Natl Inst Health Consens Dev Conf Consens Statement 1985, 5:27.

33. Anonimus: Consensus development summaries. Lowering blood cholesterol to prevent heart disease. National Institutes of Health. Conn Med 1985, 49:357-364.

34. Wallis C: Hold the Eggs and Butter. TME 1984, 123:62.

35. LaRosa JC: Reduction of serum LDL-C levels: a relationship to clinical benefits. Am J Cardiovasc Drugs 2003, 3:271-281.

36. Koenig W: Treating residual cardiovascular risk: will lipoprotein-associated phospholipase A2 inhibition live up to its promise? J Am Coll Cardiol 2008, 51:1642-1644.

37. Nilsson J, Kovanen PT: Shifting to new targets in pharmacological prevention of cardiovascular diseases. Curr Opin Lipidol 2009, 20:361-362.

38. Mitka M: Cholesterol drug lowers LDL-C levels but again fails to show clinical benefit. JAMA 2010, 303:211-212

39. Biasillo G, Leo M, Della Bona R, et al: Inflammatory biomarkers and coronary heart disease: from bench to bedside and back. Intern Emerg Med 2010, 5:225-233.

40. Thorogood M: Vegetarianism, coronary disease risk factors and coronary heart disease. Curr Opin Lipidol 1994, 5:17-21

41. Lindsay S, Chaikoff IL: Naturally occuring arteriosclerosis in animals: a comparison with experimentally induced lesions. In In Atherosclerosis and its origin. Edited by Sandler M, Bourne GH. New York: Academic Press; 1963:349-437.

42. Bohorquez F, Stout C: Arteriosclerosis in exotic mammals. Atherosclerosis 1972, 16:225-231.

43. McCullagh KG: Arteriosclerosis in the African elephant. I. Intimal atherosclerosis and its possible causes. Atherosclerosis 1972, 16:307-335.

44. Lindsay S, Chaikoff IL, Gilmore JW: Arteriosclerosis in the dog. I. Spontaneous lesions in the aorta and the coronary arteries. AMA Arch Pathol 1952, 53:281-300.

45. Finlayson R, Symons C: Arteriosclerosis in wild animals in captivity. Proc R Soc Med 1961, 54:973.

46. Finlayson R, Symons C, Fiennes RN: Atherosclerosis: a comparative study. Br Med J 1962, 1:501-507.

47. Landé KE, Sperry WM: Human atherosclerosis in relation to the cholesterol content of the blood serum. Arch Pathol 1936, 22:301-312.

48. Stehbens WE: The role of lipid in the pathogenesis of atherosclerosis. Lancet 1975, 1:724-727.

49. Stehbens WE: The hypothetical epidemic of coronary heart disease and atherosclerosis. Med Hypotheses 1995, 45:449-454.

50. Stehbens WE: Atherosclerosis: usage and misusage. J Intern Med 1998, 243:395-398.

51. Stehbens WE: Use and misuse of atherosclerosis. J Intern Med 1999, 245:311.

52. Stehbens WE: Coronary heart disease, hypercholesterolemia, and atherosclerosis. II. Misrepresented data. Exp Mol Pathol 2001, 70:120-139. 
53. Stehbens WE: Coronary heart disease, hypercholesterolemia, and atherosclerosis. I. False premises. Exp Mol Pathol 2001, 70:103-119.

54. Stehbens WE: Hypothetical hypercholesterolaemia and atherosclerosis. Med Hypotheses 2004, 62:72-78.

55. Ravnskov U: An elevated serum cholesterol level is secondary, not causal, in coronary heart disease. Med Hypotheses 1991, 36:238-241.

56. Ravnskov U: The questionable role of saturated and polyunsaturated fatty acids in cardiovascular disease. J Clin Epidemiol 1998, 51:443-460.

57. Ravnskov U: A hypothesis out-of-date. the diet-heart idea. J Clin Epidemiol 2002, 55:1057-1063.

58. Ravnskov U: The fallacies of the lipid hypothesis. Scand Cardiovasc J 2008, 42:236-239.

59. Ravnskov U: Cholesterol was healthy in the end. World Rev Nutr Diet 2009, 100:90-109.

60. Mascitelli L, Pezzetta F, Goldstein MR: Why the overstated beneficial effects of statins do not resolve the cholesterol controversy. QJM 2009, 102:435-436.

61. Fukuchi $\mathrm{M}$, Watanabe J, Kumagai $\mathrm{K}$, et al: Normal and oxidized low density lipoproteins accumulate deep in physiologically thickened intima of human coronary arteries. Lab Invest 2002, 82:1437-1447.

62. Nakashima Y, Fujii H, Sumiyoshi S, et al: Early human atherosclerosis: accumulation of lipid and proteoglycans in intimal thickenings followed by macrophage infiltration. Arterioscler Thromb Vasc Biol 2007, 27:1159-1165.

63. Stary $\mathrm{HC}$, Blankenhorn $\mathrm{DH}$, Chandler $\mathrm{AB}$, et al: $\mathrm{A}$ definition of the intima of human arteries and of its atherosclerosis-prone regions. A report from the committee on vascular lesions of the council on arteriosclerosis, american heart association. Arterioscler Thromb 1992, 12:120-134.

64. Nakashima T, Tashiro T: Early morphologic stage of human coronary atherosclerosis. Kurume Med J 1968, 15:235-242

65. Lee RT, Yamamoto C, Feng Y, et al: Mechanical strain induces specific changes in the synthesis and organization of proteoglycans by vascular smooth muscle cells. J Biol Chem 2001, 276:13847-13851.

66. Little PJ, Tannock L, Olin KL, et al: Proteoglycans synthesized by arterial smooth muscle cells in the presence of transforming growth factor-beta1 exhibit increased binding to LDLs. Arterioscler Thromb Vasc Biol 2002. 22:55-60

67. Nakashima Y, Wight TN, Sueishi K: Early atherosclerosis in humans: role of diffuse intimal thickening and extracellular matrix proteoglycans. Cardiovasc Res 2008, 79:14-23.

68. Nakashima $Y$, Chen $Y X$, Kinukawa $N$, et al: Distributions of diffuse intimal thickening in human arteries: preferential expression in atherosclerosis-prone arteries from an early age. Virchows Arch 2002, 441:279-288,

69. Subbotin VM: Analysis of arterial intimal hyperplasia: review and hypothesis. Theor Biol Med Model 2007, 4:41.

70. Thoma R: Ueber die Abhängigkeit der Bindegewebsneubildung in der Arterienintima von den mechanischen Bedingungen des Blutumlaufes. Erste Mittheilung. Die Rückwirkung des Verschlusses der Nabelarterien und des arteriösen Ganges auf die Structur der Aortenwand. Archiv fur pathologische Anatomie und Physiologie und fur Klinische Medicin (Virchows Archiv) 1883, 93:443-505.

71. Stary $\mathrm{HC}$, Blankenhorn $\mathrm{DH}$, Chandler $A B$, et al: $A$ definition of the intima of human arteries and of its atherosclerosis- prone regions. A report from the committee on vascular lesions of the council on arteriosclerosis, american heart association. Circulation 1992, 85:391-405.

72. Wolkoff K: Über die histologische Struktur der Coronararterien des menschlichen Herzens. Virchows Arch 1923, 241:42-58.

73. Stary $\mathrm{HC}$, Chandler $A B$, Glagov $S$, et al: A definition of initial, fatty streak, and intermediate lesions of atherosclerosis. A report from the committee on vascular lesions of the council on arteriosclerosis, american heart association. Circulation 1994, 89:2462-2478.

74. Ojha M, Leask RL, Butany J, et al: Distribution of intimal and medial thickening in the human right coronary artery: a study of 17 RCAs. Atherosclerosis 2001, 158:147-153.

75. Seierstad SL, Svindland A, Larsen S, et al: Development of intimal thickening of coronary arteries over the lifetime of Atlantic salmon, Salmo salar L., fed different lipid sources. J Fish Dis 2008, 31:401-413.

76. Houser S, Muniappan A, Allan J, et al: Cardiac allograft vasculopathy: real or a normal morphologic variant? $J$ Heart Lung Transplant 2007, 26:167-173.

77. Kolodgie FD, Burke AP, Nakazawa G, et al: Is pathologic intimal thickening the key to understanding early plaque progression in human atherosclerotic disease? Arterioscler Thromb Vasc Biol 2007, 27:986-989.

78. Burke AP, Farb A, Malcom GT, et al: Coronary risk factors and plaque morphology in men with coronary disease who died suddenly. N Engl J Med 1997, 336:1276-1282

79. Stary HC: An atlas of atherosclerosis: progression and regression. New York: Parthenon Publishing Group; 1999.

80. Kolodgie FD, Virmani R, Burke AP, et al: Pathologic assessment of the vulnerable human coronary plaque. Heart 2004, 90:1385-1391.

81. Shanmugam N, Roman-Rego A, Ong P, et al: Atherosclerotic plaque regression: fact or fiction? Cardiovasc Drugs Ther 2010, 24:311-317.

82. Tabas I, Williams KJ, Boren J: Subendothelial lipoprotein retention as the initiating process in atherosclerosis: update and therapeutic implications. Circulation 2007, 116:1832-1844.

83. French JE: Atherosclerosis in relation to the structure and function of the arterial intima, with special reference to the endothelium. Int Rev Exp Pathol 1966, 5:253-353.

84. Thoma R: Ueber die Abhangigkeit der Bindegewebsneubildung in der Arterienintima von den mechanischen Bedingungen des Blutumlaufes. Archiv fur pathologische Anatomie und Physiologie und fur klinische Medicin (Virchows Archiv) 1886, 105:1-28.

85. Thoma R: Über die intima der arterien. Virchows Arch 1921, 230:1-45

86. Consigny PM: Pathogenesis of atherosclerosis. AJR Am J Roentgenol 1995, 164:553-558.

87. Dellmann HD: Textbook of Veterinary Histology. Baltimore: Lippincott Williams \& Wilkins; 1998.

88. Ham AW: Histology. 9th edition. Philadelphia: Lippincott; 1987.

89. Junqueira LC, Carneiro J: Basic Histology: Text \& Atlas. 11 International Editionth edition. New York: The McGraw-Hill Companies; 2005

90. DiCorleto PE, Gimbrone MAJ: Vascular Endothelium. In In Atherosclerosis and coronary artery disease. 1st edition. Edited by Fuster V, Ross R, Topol EJ. Philadelphia: Lippincott-Raven; 1996:387-399.

91. Friedman M: Pathogenesis of coronary artery disease. New York: Blakiston Division, McGraw-Hill; 1969. 
92. Goldberg ID: The endothelium: injury and repair of the arterial wall. In In The Coronary Artery. Edited by Kalsner S. New York: Oxford University Press; 1982:417-432.

93. Huttner I, Kocher O, Gabbani G: Endothelial and smooth-muscle cells. In In Diseases of the arterial wall. Edited by Camilleri J-P, Berry CL, Fiessinger J-N, Bariety J. London: Springer-Verlag; 1989:3-41.

94. Kuehnel W: Color Atlas of Cytology, Histology, and Microscopic Anatomy. 4th edition. New York: Thieme Verlag; 2003.

95. Bacon RL, Niles NR: Medical histology: a text-atlas with introductory pathology. New York: Springer-Verlag; 1983.

96. Ross MH, Kaye Gl, Pawlina W: Histology: a text and atlas. 4th edition. Philadelphia: Lippincott Williams \& Wilkins; 2003.

97. Gartner LP, Hiatt JL: Color textbook of histology. 3rd edition. Philadelphia: Saunders/Elsevier; 2007.

98. Rosenthal N, Xavier-Neto J: From the bottom of the heart: anteroposterior decisions in cardiac muscle differentiation. Curr Opin Cell Biol 2000, 12:742-746.

99. Medscape.com [http://www.medscape.com/]

100. McPherson JA, Ahsan CH, Boudi FB: coronary artery atherosclerosis. In Medscape 2011,

101. Gallagher PJ: Blood Vessels. Chapter 33. In In Histology for Pathologists. 2nd edition. Edited by Sternberg SS. Philadelphia: Lippincott-Raven; 1997:763-786.

102. Stehbens WE: Vascular Pathology. London: Chapman \& Hall Medical; 1995.

103. Rader DJ, Daugherty A: Translating molecular discoveries into new therapies for atherosclerosis. Nature 2008, 451:904-913.

104. Rocha VZ, Libby P: Obesity, inflammation, and atherosclerosis. Nat Rev Cardiol 2009, 6:399-409.

105. Anitschkow NN: A history of experimentation on arterial atherosclerosis in animals. In In Cowdry's arteriosclerosis; a survey of the problem. 2nd edition. Edited by Blumenthal HT. Springfield, III: Thomas; 1967:22-44.

106. Geiringer E: Intimal vascularization and atherosclerosis. J Pathol Bacteriol 1951, 63:201-211.

107. Torzewski M, Navarro B, Cheng F, et al: Investigation of Sudan IV staining areas in aortas of infants and children: possible prelesional stages of atherogenesis. Atherosclerosis 2009, 206:159-167.

108. Stary HC, Chandler AB, Glagov S, et al: A definition of initial, fatty streak, and intermediate lesions of atherosclerosis. A report from the committee on vascular lesions of the council on arteriosclerosis, american heart association. Arterioscler Thromb 1994, 14:840-856.

109. Miyao Y, Kugiyama K, Kawano H, et al: Diffuse intimal thickening of coronary arteries in patients with coronary spastic angina. J Am Coll Cardiol 2000, 36:432-437.

110. Garvin MR, Labinaz M, Pels K, et al: Arterial expression of the plasminogen activator system early after cardiac transplantation. Cardiovasc Res 1997, 35:241-249.

111. Miller $\mathrm{H}$, Poon $\mathrm{S}$, Hibbert $\mathrm{B}$, et al: Modulation of estrogen signaling by the novel interaction of heat shock protein 27, a biomarker for atherosclerosis, and estrogen receptor beta: mechanistic insight into the vascular effects of estrogens. Arterioscler Thromb Vasc Biol 2005, 25:e10-14.

112. O'Brien ER, Bennett KL, Garvin MR, et al: Beta ig-h3, a transforming growth factor-beta-inducible gene, is overexpressed in atherosclerotic and restenotic human vascular lesions. Arterioscler Thromb Vasc Biol 1996, 16:576-584

113. Williams JK, Heistad DD: Structure and function of vasa vasorum. Trends Cardiovasc Med 1996, 6:53-57.

114. Moreno PR, Purushothaman KR, Sirol M, et al: Neovascularization in human atherosclerosis. Circulation 2006, 113:2245-2252.

115. Pels K, Labinaz M, O'Brien ER: Arterial wall neovascularization-potential role in atherosclerosis and restenosis. Jpn Circ J 1997, 61:893-904.

116. Atkinson C, Southwood M, Pitman R, et al: Angiogenesis occurs within the intimal proliferation that characterizes transplant coronary artery vasculopathy. J Heart Lung Transplant 2005, 24:551-558.

117. Barr J: An Address On Arterio-Sclerosis. The British Medical Journa 1905, 1:53-57.

118. Winternitz MC, Thomas RM, LeCompte PM: The Biology of Arteriosclerosis. Springfield, III: C. C. Thomas; 1938.

119. LeCompte PM: Reactions of the vasa vasorum in vascular disease. In In Cowdry's arteriosclerosis; a survey of the problem. 2nd edition. Edited by Blumenthal HT. Springfield, III: Thomas; 1967:212-224.

120. Vink A, Schoneveld AH, Poppen M, et al: Morphometric and immunohistochemical characterization of the intimal layer throughout the arterial system of elderly humans. J Anat 2002, 200:97-103.

121. Wolinsky H, Glagov S: Nature of species differences in the medial distribution of aortic vasa vasorum in mammals. Circ Res 1967, 20:409-421.

122. Sueishi K, Yonemitsu Y, Nakagawa $K$, et al: Atherosclerosis and angiogenesis. Its pathophysiological significance in humans as well as in an animal model induced by the gene transfer of vascular endothelial growth factor. Ann N Y Acad Sci 1997, 811:311-322. 322-314.

123. Heistad DD, Armstrong ML: Blood flow through vasa vasorum of coronary arteries in atherosclerotic monkeys. Arteriosclerosis 1986, 6:326-331.

124. Herrmann J, Lerman LO, Rodriguez-Porcel $M$, et al: Coronary vasa vasorum neovascularization precedes epicardial endothelial dysfunction in experimental hypercholesterolemia. Cardiovasc Res 2001, 51:762-766

125. Zhang Y, Cliff WJ, Schoefl Gl, et al: Immunohistochemical study of intimal microvessels in coronary atherosclerosis. Am J Pathol 1993, 143:164-172.

126. Sarkisov DS, Kolocolchicova EG, Varava BN, et al: Morphogenesis of intimal thickening in nonspecific aortoarteritis. Hum Pathol 1989, 20:1048-1056.

127. Kumamoto M, Nakashima Y, Sueishi K: Intimal neovascularization in human coronary atherosclerosis: its origin and pathophysiological significance. Hum Pathol 1995, 26:450-456.

128. Hildebrandt HA, Gossl M, Mannheim D, et al: Differential distribution of vasa vasorum in different vascular beds in humans. Atherosclerosis 2008, 199:47-54.

129. Nakano T, Nakashima Y, Yonemitsu Y, et al: Angiogenesis and lymphangiogenesis and expression of lymphangiogenic factors in the atherosclerotic intima of human coronary arteries. Hum Pathol 2005, 36:330-340.

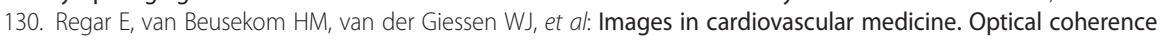
tomography findings at 5-year follow-up after coronary stent implantation. Circulation 2005, 112:e345-346.

131. Song J, Sumiyoshi S, Nakashima Y, et al: Overexpression of heme oxygenase-1 in coronary atherosclerosis of Japanese autopsies with diabetes mellitus: Hisayama study. Atherosclerosis 2009, 202:573-581. 
132. Kwon HM, Sangiorgi G, Ritman EL, et al: Enhanced coronary vasa vasorum neovascularization in experimental hypercholesterolemia. J Clin Invest 1998, 101:1551-1556.

133. Dvorak HF, Brown LF, Detmar M, et al: Vascular permeability factor/vascular endothelial growth factor, microvascular hyperpermeability, and angiogenesis. Am J Pathol 1995, 146:1029-1039.

134. Nagy JA, Benjamin L, Zeng H, et al: Vascular permeability, vascular hyperpermeability and angiogenesis. Angiogenesis 2008, 11:109-119.

135. Babin PJ, Gibbons GF: The evolution of plasma cholesterol: Direct utility or a "spandrel" of hepatic lipid metabolism? Prog Lipid Res 2009, 48:73-91.

136. Levy FH, Kelly DP: Regulation of ATP synthase subunit e gene expression by hypoxia: cell differentiation stage-specific control. Am J Physiol 1997, 272:C457-465.

137. Cliff WJ, Schoefl Gl: Pathological vascularization of the coronary intima. Ciba Found Symp 1983, 100:207-221.

138. Mause SF, Weber C: Intrusion through the fragile back door: immature plaque microvessels as entry portals for leukocytes and erythrocytes in atherosclerosis. J Am Coll Cardiol 2009, 53:1528-1531.

139. Sluimer JC, Kolodgie FD, Bijnens AP, et al: Thin-walled microvessels in human coronary atherosclerotic plaques show incomplete endothelial junctions relevance of compromised structural integrity for intraplaque microvascular leakage. J Am Coll Cardiol 2009, 53:1517-1527.

140. Takano M, Yamamoto M, Inami S, et al: Appearance of lipid-laden intima and neovascularization after implantation of bare-metal stents extended late-phase observation by intracoronary optical coherence tomography. J Am Coll Cardiol 2009, 55:26-32.

141. Ruben M: Corneal vascularization. Int Ophthalmol Clin 1981, 21:27-38.

142. Azar DT: Corneal angiogenic privilege: angiogenic and antiangiogenic factors in corneal avascularity, vasculogenesis, and wound healing (an American Ophthalmological Society thesis). Trans Am Ophthalmol SOC 2006, 104:264-302.

143. Cogan DC, Kuwabara T: Lipid keratopathy and atheroma. Trans Am Ophthalmol Soc 1958, 56:109-119. discussion 109-119.

144. Gupta D, Illingworth C: Treatments for corneal neovascularization: a review. Cornea 2011, 30:927-938.

145. Epstein RJ, Stulting RD, Hendricks RL, et al: Corneal neovascularization. Pathogenesis and inhibition. Cornea 1987, 6:250-257.

146. Al-Abdullah AA, Al-Assiri A: Resolution of bilateral corneal neovascularization and lipid keratopathy after photodynamic therapy with verteporfin. Optometry 2011, 82:212-214.

147. Chu HS, Hu FR, Yang CM, et al: Subconjunctival injection of bevacizumab in the treatment of corneal neovascularization associated with lipid deposition. Cornea 2011, 30:60-66.

148. Yeung SN, Lichtinger A, Kim P, et al: Combined use of subconjunctival and intracorneal bevacizumab injection for corneal neovascularization. Cornea 2011, 30:1110-1114.

149. Loeffler KU, Seifert P: Unusual idiopathic lipid keratopathy: a newly recognized entity? Arch Ophthalmol 2005, 123:1435-1438.

150. Duran JA, Rodriguez-Ares MT: Idiopathic lipid corneal degeneration. Cornea 1991, 10:166-169.

151. Arentsen JJ: Corneal neovascularization in contact lens wearers. Int Ophthalmol Clin 1986, 26:15-23.

152. Oh JY, Kim MK, Wee WR: Subconjunctival and intracorneal bevacizumab injection for corneal neovascularization in lipid keratopathy. Cornea 2009, 28:1070-1073.

153. Peter J, Fraenkel G, Goggin M, et al: Fluorescein angiographic monitoring of corneal vascularization in lipid keratopathy. Clin Experiment Ophthalmol 2004, 32:78-80.

154. Silva-Araujo A, Tavares MA, Lemos MM, et al: Primary lipid keratopathy: a morphological and biochemical assessment. Br J Ophthalmol 1993, 77:248-250.

155. Reddy C, Stock EL, Mendelsohn AD, et al: Pathogenesis of experimental lipid keratopathy: corneal and plasma lipids. Invest Ophthalmol Vis Sci 1987, 28:1492-1496.

156. Kazmierczak Z, Pandzioch Z: Chromatographic identification of lipids from the aqueous eye humor. Microchem J 1981, 26:399-401.

157. Koutselinis A, Kalofoutis A, Boukis S: Major Lipid Classes in Aqueous-Humor after Death. Metab Ophthalmol 1978, 2:19-21.

158. Kalofoutis A, Julien G, Boukis D, et al: Chemistry of Death.2. Phospholipid Composition of Aqueous-Humor after Death. Forensic Sci 1977, 9:229-232.

159. Olin DD, Rogers WA, Macmillan AD: Lipid-laden aqueous-humor associated with anterior uveitis and concurrent hyperlipemia in 2 dogs. J Am Vet Med Assoc 1976, 168:861-864.

160. Schmidt-Martens FW: Lipids in the aqueous humor of the cattle eye and their role as potential nutritive substrates for the cornea. Bericht uber die Zusammenkunft Deutsche Ophthalmologische Gesellschaft 1972, 71:91-95.

161. Varma SD, Reddy VN: Phospholipid Composition of Aqueous Humor, Plasma and Lens in Normal and Alloxan Diabetic Rabbits. Exp Eye Res 1972, 13:120-.

162. Herring M, Smith J, Dalsing $M$, et al: Endothelial seeding of polytetrafluoroethylene femoral popliteal bypasses: the failure of low-density seeding to improve patency. J Vasc Surg 1994, 20:650-655.

163. Jensen N, Lindblad B, Bergqvist D: Endothelial cell seeded dacron aortobifurcated grafts: platelet deposition and long-term follow-up. J Cardiovasc Surg (Torino) 1994, 35:425-429.

164. Ross R: Recent progress in understanding atherosclerosis. J Am Geriatr Soc 1983, 31:231-235.

165. Schmidt SP, Meerbaum SO, Anderson JM, et al: Evaluation of expanded polytetrafluoroethylene arteriovenous access grafts onto which microvessel-derived cells were transplanted to "improve" graft performance: preliminary results. Ann Vasc Surg 1998, 12:405-411.

166. Walpoth BH, Pavlicek M, Celik B, et al: Prevention of neointimal proliferation by immunosuppression in synthetic vascular grafts. Eur J Cardiothorac Surg 2001, 19:487-492.

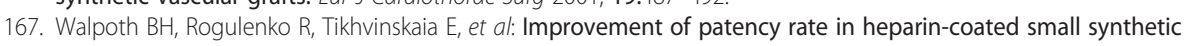
vascular grafts. Circulation 1998, 98:I319-323. discussion II324.

168. Ballermann BJ, Dardik A, Eng E, et al: Shear stress and the endothelium. Kidney Int Supp/ 1998, 67:S100-108.

169. Glagov S: Intimal hyperplasia, vascular modeling, and the restenosis problem. Circulation 1994, 89:2888-2891. 
170. Gloe T, Sohn HY, Meininger GA, et al: Shear stress-induced release of basic fibroblast growth factor from endothelial cells is mediated by matrix interaction via integrin alpha(v)beta3. J Biol Chem 2002, 277:23453-23458.

171. Karino T, Motomiya M, Goldsmith HL: Flow patterns at the major T-junctions of the dog descending aorta. J Biomech 1990, 23:537-548.

172. Sho M, Sho E, Singh TM, et al: Subnormal shear stress-induced intimal thickening requires medial smooth muscle cell proliferation and migration. Exp Mol Pathol 2002, 72:150-160.

173. Sunamura M, Ishibashi H, Karino T: Flow patterns and preferred sites of intimal thickening in diametermismatched vein graft interpositions. Surgery 2007, 141:764-776.

174. Wang H, Riha GM, Yan S, et al: Shear stress induces endothelial differentiation from a murine embryonic mesenchymal progenitor cell line. Arterioscler Thromb Vasc Biol 2005, 25:1817-1823.

175. Xu C, Lee S, Singh TM, et al: Molecular mechanisms of aortic wall remodeling in response to hypertension. J Vasc Surg 2001, 33:570-578.

176. Yamamoto K, Sokabe T, Watabe T, et al: Fluid shear stress induces differentiation of Flk-1-positive embryonic stem cells into vascular endothelial cells in vitro. Am J Physiol Heart Circ Physiol 2005, 288:H1915-1924.

177. Yamamoto K, Takahashi T, Asahara T, et al: Proliferation, differentiation, and tube formation by endothelial progenitor cells in response to shear stress. J Appl Physiol 2003, 95:2081-2088.

178. Yamauchi M, Takahashi M, Kobayashi M, et al: Normalization of high-flow or removal of flow cannot stop highflow induced endothelial proliferation. Biomed Res 2005, 26:21-28.

179. Subbotin V: Arterial intimal hyperplasia: biological analysis of the disease and possible approaches to the problem. In In New Approaches in Coronary Artery Disease 8th International Congress on Coronary Artery Disease; October 11-14, 2009; Prague, Czech Republic. Edited by Lewis BL, Widimsky P, Flugelman MY, Halon DA, Medimond. 2009:225-230.

180. Milewicz DM, Kwartler CS, Papke CL, et al: Genetic variants promoting smooth muscle cell proliferation can result in diffuse and diverse vascular diseases: evidence for a hyperplastic vasculomyopathy. Genet Med 2010, 12:196-203.

181. French JE, Jennings MA, Poole JCF, et al: Intimal Changes in the Arteries of Ageing Swine. Proc R Soc Lond B Biol Sci 1963, 158:24-42.

182. Woolf N: Pathology of Atherosclerosis. London Butterworth Scientific; 1982.

183. Osborn GR: The incubation period of coronary thrombosis; with a chapter on haemodynamics of the coronary circulation by R. F. Davis. London: Butterworths; 1963.

184. Marti HJ, Bernaudin M, Bellail A, et al: Hypoxia-induced vascular endothelial growth factor expression precedes neovascularization after cerebral ischemia. Am J Pathol 2000, 156:965-976.

185. Semenza GL: Regulation of vascularization by hypoxia-inducible factor 1. Ann N Y Acad Sci 2009, 1177:2-8

186. Hauss WH, Junge-Huelsing G, Hollander HJ: Changes in metabolism of connective tissue associated with ageing and arterio- or atherosclerosis. J Atheroscler Res 1962, 2:50-61

187. Anonimus: REPORT of committee on nomenclature of the american society for the study of arteriosclerosis; tentative classification of arteriopathies. Circulation 1955, 12:1065-1067.

188. Anonymus: Atherosclerosis: a report by the National Heart and Lung Institute Task Force on Atherosclerosis. (Department of Health EaWNloH ed., vol. 2: DHED Publication No. (NIH) 72-219; 1971.

189. Moschcowitz E: Hyperplastic arteriosclerosis versus atherosclerosis. J Am Med Assoc 1950, 143:861-865.

190. Shapiro WD: Coronary disease in the young. Dissertation. University of Wisconsin, Medicine; 1951.

191. Stehbens WE: Atherosclerosis and Degerative Diseases of Blood Vessels. In In Vascular Pathology. Edited by Stehbens WE, Lie JT. London: Chapman \& Hall Medical; 1995:175-269.

192. Thomas WA, Kim DN: Biology of disease. Atherosclerosis as a hyperplastic and/or neoplastic process. Lab Invest 1983, 48:245-255.

193. Ross R: The pathogenesis of atherosclerosis-an update. N Engl J Med 1986, 314:488-500

194. Fishbein GA, Fishbein MC: Arteriosclerosis: rethinking the current classification. Arch Pathol Lab Med 2009, 133:1309-1316.

doi:10.1186/1742-4682-9-11

Cite this article as: Subbotin: Neovascularization of coronary tunica intima (DIT) is the cause of coronary atherosclerosis. Lipoproteins invade coronary intima via neovascularization from adventitial vasa vasorum, but not from the arterial lumen: a hypothesis. Theoretical Biology and Medical Modelling 2012 9:11.

\section{Submit your next manuscript to BioMed Central and take full advantage of:}

- Convenient online submission

- Thorough peer review

- No space constraints or color figure charges

- Immediate publication on acceptance

- Inclusion in PubMed, CAS, Scopus and Google Scholar

- Research which is freely available for redistribution 